\title{
Chemical and electrical properties of LSM cathodes prepared by
}

\section{mechanosynthesis}

\author{
R. Moriche*1,2 ${ }^{1,}$ D. Marrero-López ${ }^{3}$, F. J. Gotor ${ }^{1}$ and M. J. Sayagués ${ }^{1}$ \\ ${ }^{1}$ Instituto de Ciencia de Materiales de Sevilla, Centro Mixto CSIC-US, Américo Vespucio 49, 41092 \\ Sevilla, Spain. \\ ${ }^{2}$ Departamento de Ciencia e Ingeniería de Materiales, Universidad Rey Juan Carlos, C/Tulipán s/n, \\ 28933 Móstoles, Madrid, Spain. \\ ${ }^{3}$ Departamento de Física Aplicada I, Facultad de Ciencias, Universidad de Málaga, Campus Teatinos s/n, \\ 29071 Málaga, Spain. \\ *Corresponding author: rocio.moriche@urjc.es; phone: 0034914888083
}

\begin{abstract}
Mechanosynthesis of $\mathrm{La}_{1-\mathrm{x}} \mathrm{Sr}_{\mathrm{x}} \mathrm{MnO}_{3}(\mathrm{x}=0,0.25,0.5,0.75$ and 1$)$ was carried out at room temperature from stoichiometric mixtures of $\mathrm{La}_{2} \mathrm{O}_{3}, \mathrm{Mn}_{2} \mathrm{O}_{3}$ and $\mathrm{SrO}$, obtaining monophasic powders with the perovskite structure. Physical properties of these materials and their chemical compatibility with the electrolyte yttria stabilized zirconia (YSZ), which depend strongly on the $\mathrm{La} / \mathrm{Sr}$ ratio, were evaluated to corroborate availability to be implemented as cathode material in solid oxide fuel cells (SOFCs). Electrical conductivity values in air ranged between $100-400 \mathrm{Scm}^{-1}$ in the temperature range of $25-850{ }^{\circ} \mathrm{C}$. Samples presented low reactivity with YSZ in the working temperature range $\left(600-1000{ }^{\circ} \mathrm{C}\right)$ maintaining the grain size small enough to preserve the catalytic activity for oxygen reduction.
\end{abstract}

Keywords: Solid Oxide Fuel Cells, LSM, mechanochemistry, perovskite structure 


\section{Introduction}

Solid Oxide Fuel Cells (SOFCs) have been widely studied in the last decade in order to reach a blue economy concept: "a zero emission world" [1]. SOFCs are specially interesting because of their advantages respect to the other types of fuel cells: theoretical efficiency of 80-90\%, lower costs, fuel flexibility and better stability with time, although the operation temperature is still too high between $800-1000{ }^{\circ} \mathrm{C}$ for practical application $[2,3]$.

Different mixed ionic-electronic conductors with perovskite structure have been proposed in the last few years as potential cathode materials for SOFC, such as cobaltites, ferrites, nickelates and double perovskites [3]; however, they usually exhibit chemical and thermal expansion incompatibilities with yttria stabilized zirconia (YSZ) electrolyte. Sr-doped lanthanum manganites, $\mathrm{La}_{1-\mathrm{x}} \mathrm{Sr}_{\mathrm{x}} \mathrm{MnO}_{3}$ (LSM), are the most common cathode material used in SOFC systems due to their high stability under oxidant atmospheres and high temperatures compared to other alternative materials [4].

Synthesis of these materials has been extensively studied using different synthetic routes, but the mechanochemical method itself (not as activation) is not yet a common one [5]. Mechanochemistry is a relative simple process that uses high-energy ball mills and permits production among others of nanostructured mixed oxides [6]. The mechanical energy from impact and shear forces by application of a high frequency movement is transferred to the powder inducing solid state chemical reactions. One of the most important advantages of mechanochemistry is its capability to produce large material quantities at room temperature and in a very short time.

In the present work, a study of the chemical and physical properties of $\mathrm{La}_{1-\mathrm{x}} \mathrm{Sr}_{\mathrm{x}} \mathrm{MnO}_{3}$ (LSM) system obtained by mechanosynthesis was carried out as small differences in the $\mathrm{La} / \mathrm{Sr}$ ratio cause significant changes in the cathode performance. A structural study of 
this system, also prepared by mechanochemistry, was recently published by Sayagués et al. [7], although smaller amounts of samples were synthesized. A summary of the obtained structural results is presented here also to demonstrate the scalability of mechanochemistry. Chemical compatibility between cathode and electrolyte and electrical properties of the cathode were measured in a cell that was built using the synthesized LSM as cathode and YSZ as electrolyte.

\section{Experimental}

$\mathrm{La}_{1-\mathrm{x}} \mathrm{Sr}_{\mathrm{x}} \mathrm{MnO}_{3}$ powder samples with different $\mathrm{Sr}$ content $(\mathrm{x}=0,0.25,0.5,0.75$ and 1) were synthesized by a mechanochemical method using a planetary ball mill (model Micro-Mill Pulverisette 7, Fritsch) from stoichiometric mixtures of $\mathrm{La}_{2} \mathrm{O}_{3}$ (Aldrich $99.98 \%$ ), $\mathrm{Mn}_{2} \mathrm{O}_{3}$ (Aldrich $99 \%$ ) and $\mathrm{SrO}$. The last one was obtained from calcination of $\mathrm{SrCO}_{3}$ (Aldrich $98 \%$ ) at $1200{ }^{\circ} \mathrm{C}$ for $12 \mathrm{~h}$. This oxide mixture was placed into a hardened chromium steel jar along with $7 \mathrm{WC}$ balls $(26.4 \mathrm{~g} ; \varnothing=15 \mathrm{~mm})$ and was milled at $600 \mathrm{rpm}$ (disc and vial) in air to obtain $6 \mathrm{~g}$ of each sample. The different compositions and the required milling time to obtain single phase powders ( $\mathbf{P}$ samples) are presented in Table I. $\mathbf{P}$ samples were then uniaxially pressed into pellets of $12 \times 5$ $\mathrm{mm}$ (microstructural characterization) or $12 \times 1 \mathrm{~mm}$ (total conductivity) and sintered in air at $1300{ }^{\circ} \mathrm{C}$ for $8 \mathrm{~h}$ with a heating rate of $10{ }^{\circ} \mathrm{Cmin}^{-1}$ and free cooling (H samples).

Structural characterization and phase identification were carried out by a PANalytical X'Pert Difractometer. X-Ray Diffraction (XRD) patterns were scanned between $10-80^{\circ}$ in $2 \theta$ and step-scan mode, using a step of $0.05^{\circ}$ and an acquisition time of 320 s. Peaks were indexed using X'Pert HighScore Plus and FullProff and WinPlot softwares $[8,9]$ were used to do the fitting and calculate the cell parameters and the 
diffraction domain size (D). Scanning electron microscopy (SEM) images were obtained on Hitachi S5800 SEM-FEG (H samples) and Hitachi S-2400N (the electrodeelectrolyte interface) microscopes. The compositional variation through the interface was analyzed using Energy Dispersive X-ray Spectroscopy (EDX) in Hitachi S-2400N, which was equipped with a Bruker detector. Transmission Electron Microscopy (TEM and HRTEM) images and electron diffraction (ED) patterns were performed on a 200 kV Philips CM200 microscope equipped with a supertwin objective lens and a $\mathrm{LaB}_{6}$ filament (point resolution $=0.25 \mathrm{~nm}$ ) and a $300 \mathrm{kV}$ TECNAI G2 F30 microscope with a field emission system (point resolution=0.2 nm). The analysis of the HRTEM images was done with the Digital Micrograph software (Gatan Inc.). The samples were prepared by dispersion of the powder in acetone and droplets of the suspension were deposited onto a coated carbon copper grid.

The total conductivity of the pellets (H samples) was determined by the four-point Van der Pauw method between 100 and $900{ }^{\circ} \mathrm{C}$ during the cooling process [10]. The area-specific polarisation resistance (ASR) values were obtained under symmetrical atmospheres in a two electrode configuration. Dense YSZ pellets $\left(8 \% \mathrm{Y}_{2} \mathrm{O}_{3}\right.$ Tosoh), of $10 \mathrm{~mm}$ of diameter and $1 \mathrm{~mm}$ of thickness were obtained at $1400{ }^{\circ} \mathrm{C}$ for $5 \mathrm{~h}$. The symmetrical cell of LSM cathode and YSZ electrolyte was prepared by screen printing using a slurry of $50 \mathrm{wt} \%$ LSM (P samples) and $50 \mathrm{wt} \%$ Terpineol; and then sintered at $1100{ }^{\circ} \mathrm{C}$ for $1 \mathrm{~h}[10]$. Impedance spectra of the cells was performed using a Solartron 1260 FRA, at open circuit voltage (OCV), in the $0.01-10^{6} \mathrm{~Hz}$ frequency range with an $a c$ signal amplitude of $50 \mathrm{mV}$. The spectra was analysed by using the ZView software [11]. 


\section{Results and Discussion}

\subsection{Microstructural and structural analysis}

XRD results of the $\mathrm{La}_{1-\mathrm{x}} \mathrm{Sr}_{\mathrm{x}} \mathrm{MnO}_{3}$ samples obtained by mechanochemistry are presented in Figure 1a. In the powder samples P1-P4, all the maxima were indexed in a pseudo-cubic symmetry $(P m-3 m, 221)$ because the small size of coherent diffraction domains (the peaks are wide) did not allow resolving the real crystal symmetry. However, sample P5 $(\mathrm{x}=1)$ exhibited some extra XRD peaks that indicated the formation of the hexagonal symmetry $\left(P 6_{3 / m m c}, 194\right)$. Similar results were found in our previous work [7]; although in that case all milled samples presented the pseudo-cubic symmetry (Fig. 2 in ref. [7]). This difference could be due to the higher milling intensity regime used in [7] (ball-to-powder ratio (BPR) of 92 instead of 31 as in present work), which probably induced a further decreasing of the coherent diffraction domains. After the sintering treatment (Fig. 1b), samples P1-P4 developed the rhombohedral structure ( $R-3 c, 167 ;$ H1-H4 samples), whereas sample P5 maintained the same hexagonal symmetry (H5). Unit cell dimensions for each phase and the average crystallite sizes (D) are presented in Table II. As can be deduced from the large broadening of reflections in Fig. 1a the crystalline domain of the as-prepared samples is very small, around $15 \mathrm{~nm}$. Comparing $\mathbf{H}$ and $\mathbf{P}$ samples, the size of the diffraction domains of sintered samples has significantly increased (about $200 \mathrm{~nm}$ ) as can be inferred from the narrower XRD peaks observed (Fig. 1b).

When $\mathrm{La}^{3+}$ is substituted for $\mathrm{Sr}^{2+}$ in $\mathrm{LaMnO}_{3}$ lattice, an amount of $\mathrm{Mn}^{3+}$ converts into $\mathrm{Mn}^{4+}$ to maintain the crystal electroneutrality and the anisotropic deformation due to the Jahn-Teller effect is reduced. If the lattice parameters of the samples are analyzed (Table II; P5 parameters could not be calculated appropriately since all the hexagonal peaks were not sufficiently resolved), it can be observed that when x value increases, $a$ 
parameter decreases (for both $\mathbf{P}$ and $\mathbf{H}$ samples) while the solid solution remains. However, when the total La is substituted by $\mathrm{Sr}(\mathbf{H 5}), a$ parameter shows an increase as a result of the change in the symmetry group $\left(P 6_{3} m m c, 194\right)$. Simultaneously, an increase of $c$ parameter (for $\mathbf{H}$ samples) occurs from $\mathrm{x}=0$ to $\mathrm{x}=0.5$ and then it slightly decreases for $\mathrm{x}=0.75$. This variation in $c$ parameter can be caused by a preferential occupation of atom positions in the cell as it was proposed by Jang et al. [12]. Finally, $c$ achieves a value of $9.0762 \AA$ for $\mathbf{H 5}$ sample given place to the hexagonal structure. All of these effects are reflected in a volume cell variation resulting in a decrease from $353.05 \AA^{3}$ to $338.67 \AA^{3}$ in the solid solution as Sr content increases. For $\mathbf{H 5}$ with a $100 \%$ in Sr content the cell volume further diminishes reaching a value of $233.24 \AA^{3}$; again this change is due to the formation of the new hexagonal unit cell with smaller $c$ parameter.

Relative density measurement of the pellets (H samples) has shown values close to $80 \%$ (Table II), showing a slight increase with increasing the Sr content while maintaining the solid solution (the rhombohedral structure). However, for $x=1($ H5), where there is a structural change, the relative density slightly decreases.

SEM and TEM representative results of the powder and sintered samples (P1, P3, $\mathbf{H 1}$ and $\mathbf{H 3}$ ) are presented in Fig 2 and 3 respectively. The microstructure of $\mathbf{P}$ samples observed by SEM is very similar for all of them, being formed by agglomerations of small particles. Representative micrographs corresponding to samples P1 and P3 are presented in fig 2(a-b). However the particle size of $\mathbf{H}$ samples varies as a function of the $\mathrm{La} / \mathrm{Sr}$ ratio and representative micrographs are presented in Figure 2 (c-d) for $\mathbf{H 1}$ and $\mathbf{H 3}$ samples. $\mathbf{H 1}\left(\mathrm{LaMnO}_{3}\right)$ shows an average grain size of $2 \mu \mathrm{m}$ (Fig. $\left.2 \mathrm{c}\right)$ and $\mathbf{H 3}$ sample (Fig. 2d), with a higher $\mathrm{Sr}$ content, shows an average grain size of $0.5 \mu \mathrm{m}$. Both images show faceted shape crystals, presenting several truncated prisms. It is worth 
noting that the presence of faceted growth can improve the catalytic properties of samples due to an increase in the specific surface area.

Figure 3 shows the TEM, ED and HRTEM results for the P1, P3, H1 and H3 samples. The powder samples $\mathbf{P 1}$ and $\mathbf{P 3}$ are formed by agglomerated particles as seen in the TEM images (left). The crystal diffraction domain is very small as can be deduced from the analysis of the corresponding electron diffraction patterns (inset) and the HRTEM micrographs (right). Some crystal domains are marked in the HRTEM images and the size is between 5 and $20 \mathrm{~nm}$. In all of the domains (110) interplanar spacing was measured and this distance could be indexed in both, the cubic and the rhombohedral system; it was indexed in the cubic perovskite structure $(\mathbf{P})$ to be coherent with the X-ray results. The crystal size for the sintered samples (H1 and H3) has increased considerably as observed by SEM. A wide dispersion of sizes from 100 nm to 2 microns was found. The H1image (left) shows an oriented crystal along the [122] zone axis of the rhombohedral structure, as indicated by the EDP (inset) and the HRTEM micrographs is presented on the right where the interplanar spacing and the ( $h k l)$ planes are marked. TEM image shown for $\mathbf{H 3}$ sample presents an elongated shape particle with different contrast in the tip; that correspond to two different oriented crystalline domains as can be deduced from the corresponding ED patterns (inset). One of them is oriented along the [001] rhombohedral structure; it is very easy to distinguish the hexagonal symmetry in the contrast of the HRTEM micrograph presented on the left (the (110) planes and spacing are depicted). HRTEM image of the second crystalline domain is presented to the right and belongs to the cubic perovskite structure oriented along [001], the (100) planes have been marked in the image.

All of these results are in accordance with our previous work [7], which demonstrates the scalability of mechanosynthesis as it is possible to obtain $6 \mathrm{~g}$ instead 
of $2 \mathrm{~g}$ (in $1 \mathrm{~h}$ of milling) of LSM material only by incrementing slightly the milling time (see table I). This makes evident some of the advantages of mechanochemistry over other synthetic methods, since the traditional ceramic method requires a temperature of $1000-1200{ }^{\circ} \mathrm{C}$ [13]; or its scalability contrasted with Pechini, citrate [14] or plasmaspraying methods [15-17].

\subsection{Cathode-Electrolyte Interface}

Chemical compatibility between the electrodes and the electrolyte is an important aspect because different materials are in contact for a prolonged time at high temperature what can promotes reactivity and cation diffusion between the components, affecting negatively the cell performance. A mixture of powders 50:50 wt.\% composed of $\mathrm{La}_{1-\mathrm{x}} \mathrm{Sr}_{\mathrm{x}} \mathrm{MnO}_{3}$ and $\mathrm{YSZ}$ electrolyte has been prepared and annealed in a furnace for $24 \mathrm{~h}$ in a range of temperatures from 800 to $1300{ }^{\circ} \mathrm{C}$. The mixture after heating was analyzed by $\mathrm{XRD}$ and the results for $\mathrm{x}=0$ and $\mathrm{x}=0.25$ are shown in Fig. 4 , the presence or absence of new products as a consequence of the reaction between LSM and YSZ was studied.

Phases with low Sr content $(\mathrm{x}=0.25)$ showed low chemical reaction with YSZ in all the temperature range studied. Otherwise, for a $\mathrm{Sr}$ content of $\mathrm{x}=0.5$, a reaction between $\mathrm{Sr}-$ and $\mathrm{Zr}-$ containing phases takes place leading to the formation of $\mathrm{SrZrO}_{3}$ as reaction product at $1300{ }^{\circ} \mathrm{C}$, however there is not reaction below $1000{ }^{\circ} \mathrm{C}$, this fact is important as the SOFCs usually works below this temperature .

The LSM/YSZ interface of symmetrical cells prepared by screen printing and sintered at $1100{ }^{\circ} \mathrm{C}$ for $1 \mathrm{~h}$ was also studied by SEM and EDX to analyze the chemical composition through the cathode-electrolyte interface and elucidate the possible interdiffusion of the different elements. SEM micrographs of the cross section of 
interfaces with different Sr compositions are shown in Figure 5. All cathodes present adequate porosity and apparently good contact with the electrolyte. As could be expected, the LSM grains have grown less than for $\mathbf{H}$ samples sintered at $1300{ }^{\circ} \mathrm{C}$. LSM samples with $\mathrm{x}=0$ and $\mathrm{x}=0.25$ have grain sizes of $\sim 1 \mu \mathrm{m}$, slightly smaller than a commercial sample of Praxair $\left(\mathrm{La}_{0.8} \mathrm{Sr}_{0.2} \mathrm{MnO}_{3}\right)$, also shown in Figure $5 \mathrm{f}$ for a comparison purpose. For larger $\mathrm{x}$ value samples, the grain size decreases with increasing the Sr content, reaching very small values of less than $0.5 \mu \mathrm{m}$ for $\mathrm{SrMnO}_{3}$. In this case the variation trend is reversed when compared with $\mathbf{H}$ samples, probably due to the different sintering temperature and way of preparing the bulk sample.

EDX line profiles for $\mathrm{La}, \mathrm{Sr}, \mathrm{Mn}, \mathrm{Y}$ and $\mathrm{Zr}$ were carried out through the interface and representative results (for $\mathrm{x}=0.25$ and 0.5 ) are presented in Figure 6. It could be deduced that for higher $\mathrm{Sr}$ contents, $\mathrm{Zr}$ diffusion into the cathode layer is more pronounced, reaching a penetration distance of $1 \mu \mathrm{m}$ for $\mathrm{La}_{0.25} \mathrm{Sr}_{0.75} \mathrm{MnO}_{3}$. These results are in agreement with the formation of $\mathrm{SrZrO}_{3}$ previously observed by XRD analysis as product of reaction between components. The apparent diffusion of $\mathrm{La}, \mathrm{Sr}$ and $\mathrm{Mn}$ elements is due to cathode particles detachment, deposited on the analyzed surfaces.

\subsection{Electrical properties}

The substitution of $\mathrm{Sr}^{2+}$ for $\mathrm{La}^{3+}$ increases the content of $\mathrm{Mn}^{4+}$ in the structure as it has been mentioned above, creating electronic holes for keeping charge neutrality [18]. For this reason, LSM is p-type electronic conductor under oxidant atmosphere $[19,20]$ :

$$
\mathrm{La}_{1-x} \mathrm{Sr}_{x} \mathrm{MnO}_{3} \longrightarrow \mathrm{La}^{3+}{ }_{1-x} \mathrm{Sr}^{2+}{ }_{x} \mathrm{Mn}^{3+}{ }_{1-x} \mathrm{Mn}^{4+}{ }_{1-x} \mathrm{O}_{3}
$$

But not only electronic conductivity is present, also ionic conductivity due to the fact that vacancies are introduced for non-stoichiometric oxygen content and aliovalent 
substitution. This kind of defects is powered by mechanosynthesis as shear forces and impacts are applied to powders.

Figure 7 shows the total conductivity of the sintered $\mathbf{H}$ samples measured by fourpoint method. It can be seen that the electrical conductivity is considerably improved by incorporating $\mathrm{Sr}^{2+}$ in the structure. Particularly, $\mathrm{Sr}$ contents of $\mathrm{x}=0.50$ and 0.75 reached conductivity values in the range of approximately $\sim 200-300 \mathrm{Scm}^{-1}$. These values are comparable to those reported in literature: $\sim 200 \mathrm{Scm}^{-1}$ in the temperature range of 600$900^{\circ} \mathrm{C}$ for samples obtained by the Pechini's method [4] and superior to a composition $\mathrm{La}_{0.85} \mathrm{Sr}_{0.15} \mathrm{MnO}_{3}\left(65 \mathrm{Scm}^{-1}\right)$ synthesized by co-precipitation [21]. A feature that can be extracted from the graph is the ferromagnetic-paramagnetic transition at $71{ }^{\circ} \mathrm{C}$ for $\mathrm{x}=$ 0.25. A magnetic behavior change for some compositions in LSM has been reported in some works [22-24].

Polarization resistance values are presented in Figure $7 \mathrm{~b}$. It can be seen that a resistance lower than $0.5 \Omega \mathrm{cm}^{2}$ is achieved at $800{ }^{\circ} \mathrm{C}$ for the compositions $\mathrm{x}=0.25$ and $\mathrm{x}=0.50$. At lower temperatures this resistance is high enough to restrict their use to medium-high temperatures. The values of polarization resistance are compared with a commercial sample of Praxair and composition $\mathrm{La}_{0.8} \mathrm{Sr}_{0.2} \mathrm{MnO}_{3}$. As it can be seen the values of polarization resistance for the samples prepared in this work are comparable to the commercial sample in the high temperature range $>700{ }^{\circ} \mathrm{C}$, but somewhat lower in the low temperature region.

Representative impedance spectra for the symmetrical cells LSM/YSZ/LSM are shown in Figure 8 . The spectra show similar features with two overlapped arcs, suggesting the presence of at least two limiting processes. These spectra were analysed with an equivalent circuit to obtain the overall polarization resistance. The equivalent circuit used in the fitting is schematically shown in the inset of Figure 8, where $L$ 
represents the inductance of the equipment, $R_{s}$ is a serial resistance including all ohmic resistances of the cell and $R_{i}$ is the polarisation resistance of each limiting process. The fitting curve is plotted as solid line in the Figure 8.

\section{Conclusions}

From discussed results it is possible to conclude that LSM system $\left(\mathrm{La}_{1-\mathrm{x}} \mathrm{Sr}_{\mathrm{x}} \mathrm{MnO}_{3}\right)$ can be obtained by mechanochemical methods at room temperature and ambient atmosphere, using short milling times. An increment of Sr content in the solid solution, which remains up to $\mathrm{x}=0.75$, carries a minor grain size growth during sintering and less compatibility with YSZ electrolyte. Taking into account the electrical properties and chemical compatibility, the best sample for its implementation as cathode in SOFCs is $\mathrm{La}_{0.5} \mathrm{Sr}_{0.5} \mathrm{MnO}_{3}$, which presents the highest total conductivity combined with a low ASR and a small grain size that presumes a better catalytic behavior. This composition is close to that found in the bibliography, where ideal compositions vary from 0.25 to 0.40 [25]. Deviations are possibly due to parameters as grain size, presence of defects and oxygen non-stoichiometry. The mechanochemistry technique to synthesize LSM powders proves to be scalable, which is very useful to obtain cathodes to be used in SOFCs industry.

\section{Acknowledgements}

This work was supported by the Spanish Government under grant no. MAT2010-17046. 


\section{References}

[1] http://www.blueeconomyalliance.com/ (2013).

[2] X. M. Ge, Y.N. Fang, S.H. Chan, Fuel Cells 12 (2012) 61-76.

[3] A.J. Jacobson, Chem. Mater. 22 (2010) 660-674.

[4] J.X. Wang, Y.K. Tao, J. Shao, W.G. Wang, J. Power Sources 186 (2009) $344-648$.

[5] M. Wang, K.D. Woo, C.G. Lee, Energy Conversion and Management 52 (2011) $1589-1592$.

[6] P. Balaz, M. Achimovicova, M. Balaz, P. Billik, Z. Cherkezova-Zheleva, J. M. Criado, F. Delogu, E. Dutkova, E. Gaffet, F. J. Gotor, R. Kumar, I. Mitov, T. Rojac, M. Senna, A. Streletskii and K. Wieczorek-Ciurowa, Chem. Soc. Reviews 42 (2013) 7571-7637.

[7] M.J. Sayagués, J.M. Córdoba, F.J. Gotor, J. Solid State Chem. 188 (2012) $11-16$.

[8] J. Rodríguez-Carvajal, Powder Diffraction Meeting, Toulouse, France, (1990) $127-128$.

[9] J. Rodríguez-Carvajal, T. Roisnel, Newsletter 20 (1998) 1-47.

[10] J. Peña-Martínez, D. Marrero-López, J.C. Ruiz-Morales, P. Núñez, C. SánchezBautista, A.J. Dos Santos-García, J. Canales-Vázquez, Int. J. of Hydrogen Energy 34 (23) (2009) 9486-9495.

[11] J.D. Johnson, ZView, A Software Program for IES Analysis, Version 2.8, Scribner Associates, Inc. Southern Pines, NC (2002).

[12] Y.H. Jang, Y. Lansac, F. Gervais, Y. Lansac, J. Chem Phys. 131 (2008) 1-8.

[13] L. Zhang, Y. Zhang, Y.D. Zhen, S.P. Jiang, J. Am. Ceram. Soc. 90 (2007) 1406-1411.

[14] J.H. Choi, J.H. Jang, J.H. Ryu, S.M. Oh, J. Power Sources 87 (2000) 92-100. 
[15] R.I.C. Rousseau, M. Nikravech, L. Benabdelmoume, C.E.D. Guyon, D. Morvan, J. Amouroux, J. Appl. Electrochem. 37 (2007) 95-101.

[16] C. Monterrubio-Badillo, H. Ageorges, T. Chartier, J.F. Coudert, P. Fauchais, Surface and Coatings Technology 200 (2006) 3743-3756.

[17] X. Wang, C. Li, C. Li, G. Yang, Inter. J. Hydrogen Energy 35 (2010) $3152-3158$.

[18] K. Nakamura, J. Solid State Chem. 173 (2003) 299-308.

[19] C. Sun, R. Hui, J. Roller, J. Solid State Electrochem. 14 (2009) 1125-1144.

[20] J. Richter, P. Holtappels, T. Graule, T. Nakamura, L.J. Gauckler, Monatshefte Für Chemie - Chemical Monthly 140 (2009) 985-999.

[21] M. Marinsek, Materials and Technology 43 (2009) 79-84.

[22] S.J. May, P.J. Ryan, J.L. Robertson, J.W. Kim, T.S. Santos, E. Karapetrova, J.L. Zarestky, X. Zhai, S.G.E. Velthuis, J.N. Eckstein, S.D. Bader, A. Bhattacharya, Nat. Mater. 8 (2009) 892-897.

[23] J. Yang, Y.Q. Ma, B.C. Zhao, W.J. Lu, R. Ang, W.H. Song, Y.P. Sun, Solid State Commun. 134 (2005) 443-447.

[24] S.P. Liu, Y. Xie, J. Xie, G.D. Tang, J. App. Phys. 110 (2011) 123714-123719.

[25] K. Kakinuma, S. Machida, K. Horiuchi, S. Hasunuma, H. Yamamura, T. Atake, Solid State Ionics 177 (2006) 2159-2154. 


\section{Figure Captions}

Figure 1. XRD patterns for all synthesized samples: (a) P1-P5 and (b) H1-H5 $(\bullet P m-3 m$ cubic perovskite structure, $\bullet-3 c$ rhombohedral structure and $* P 6_{3} / m m c$ hexagonal structure).

Figure 2. TEM images, ED pattern and HRTEM micrographs of the P1, P3 , H1 and H3. samples. HRTEM micrograph show measured interplanar spacing and the size of the domain in the case of P1 and P3.

Figure 3. SEM images of powder and sintered samples: (a) P1; (b) H1, (c) P3 and (d) H3.

Figure 4. XRD of LSM-YSZ powder mixtures annealed in the range $800-1300{ }^{\circ} \mathrm{C}$ during $24 \mathrm{~h}$ for $\mathrm{x}=0$ and $\mathrm{x}=0.25$ samples $\left(\bullet \mathrm{LSM}, * \mathrm{YSZ}, \bullet^{\mathrm{SrZrO}}{ }_{3}\right)$.

Figure 5. SEM micrographs of the cathode-electrolyte interface: (a) $x=0$, (b) $x=0.25$, (c) $\mathrm{x}=0.5$ and (c) commercial Praxair sample to be compared. The top of each image is formed by the LSM cathode and the bottom by the YSZ electrolyte.

Figure 6. EDX chemical profiles at the LSM-YSZ interface for (a) $\mathrm{x}=0.25$ and (b) $\mathrm{x}=$ 0.5 .

Figure 7. Electrical properties of LSM samples: (a) total conductivity by four-point method and (b) polarization resistance measurements by ion blocking cell.

Figure 8. Impedance spectra at $700{ }^{\circ} \mathrm{C}$ in air for the symmetrical cells LSM/YSZ/LSM at open circuit conditions. The solid line is the fitting result using the equivalent circuit of the inset figure. 
Table I. Composition of the synthesized powder samples and milling time required to obtain $6 \mathrm{~g}$ of pure phases.

\begin{tabular}{lc}
\hline Phase & t (min) \\
\hline $\mathbf{P 1}\left(\mathrm{LaMnO}_{3}\right)$ & 90 \\
\hline $\mathbf{P 2}\left(\mathrm{La}_{0.75} \mathrm{Sr}_{0.25} \mathrm{MnO}_{3}\right)$ & 90 \\
\hline $\mathbf{P 3}\left(\mathrm{La}_{0.5} \mathrm{Sr}_{0.5} \mathrm{MnO}_{3}\right)$ & 120 \\
\hline $\mathbf{P 4}\left(\mathrm{La}_{0.25} \mathrm{Sr}_{0.75} \mathrm{MnO}_{3}\right)$ & 120 \\
\hline $\mathbf{P 5}\left(\mathrm{SrMnO}_{3}\right)$ & 150 \\
\hline
\end{tabular}

Table II. Space Group, Cell Parameters, Diffraction domain size and relative density obtained for $\mathrm{P}$ (powder) and heated $(\mathrm{H})$ samples.

\begin{tabular}{|c|c|c|c|c|c|c|}
\hline Sample & $\begin{array}{l}\text { Space } \\
\text { Group }\end{array}$ & $\begin{array}{c}\mathbf{a}(\AA) \\
\mathbf{P}[\mathbf{\pm 0 . 0 0 2}] \\
\mathbf{H}[ \pm \mathbf{0 . 0 0 0 1}]\end{array}$ & $\begin{array}{c}\text { c }(\AA) \\
\mathbf{P}[\mathbf{\pm 0 . 0 0 2}] \\
\mathbf{H}[\mathbf{\pm 0 . 0 0 0 1 ]}\end{array}$ & $\mathbf{V}\left(\AA^{\mathbf{3}}\right)$ & $\underset{(\mathbf{n m})}{\mathbf{D}}$ & $\begin{array}{c}\text { Relative } \\
\text { Density } \\
(\%)\end{array}$ \\
\hline \multirow{2}{*}{$\begin{array}{c}\text { P1 } \\
\mathrm{LaMnO}_{3} \\
\mathbf{H 1}\end{array}$} & $P m-3 m$ & 3.917 & - & 60,10 & 15 & - \\
\hline & $R-3 c$ & 5.5258 & 13.3510 & 353.05 & 120 & 79.8 \\
\hline \multirow{2}{*}{$\begin{array}{c}\mathbf{P 2} \\
\mathrm{La}_{0.75} \mathrm{Sr}_{0.25} \mathrm{MnO}_{3} \\
\mathbf{H 2} \\
\end{array}$} & $P m-3 m$ & 3.882 & - & 58.50 & 12 & - \\
\hline & $R-3 c$ & 5.5138 & 13.3612 & 351.79 & 240 & 81.5 \\
\hline \multirow{2}{*}{$\begin{array}{c}\mathbf{P 3} \\
\mathrm{La}_{0.5} \mathrm{Sr}_{0.5} \mathrm{MnO}_{3} \\
\mathbf{H 3}\end{array}$} & $P m-3 m$ & 3.862 & - & 57,60 & 18 & - \\
\hline & $\mathrm{R}-3 \mathrm{c}$ & 5.4450 & 13.3813 & 343.58 & 113 & 87.1 \\
\hline \multirow{2}{*}{$\begin{array}{c}\mathrm{P} 4 \\
\mathrm{La}_{0.25} \mathrm{Sr}_{0.75} \mathrm{MnO}_{3} \\
\mathbf{H 4}\end{array}$} & $P m-3 m$ & 3.849 & - & 57.02 & 13 & - \\
\hline & $R-3 c$ & 5.4280 & 13.2731 & 338.67 & 211 & 87.9 \\
\hline \multirow{2}{*}{$\begin{array}{c}\mathrm{P5} \\
\mathrm{SrMnO}_{3} \\
\mathbf{H 5}\end{array}$} & $\mathrm{PG}_{3} / m m c$ & - & - & - & 15 & - \\
\hline & $\mathrm{P}_{3} / m m c$ & 5.4473 & 9.0762 & 233.24 & 200 & 82.5 \\
\hline
\end{tabular}




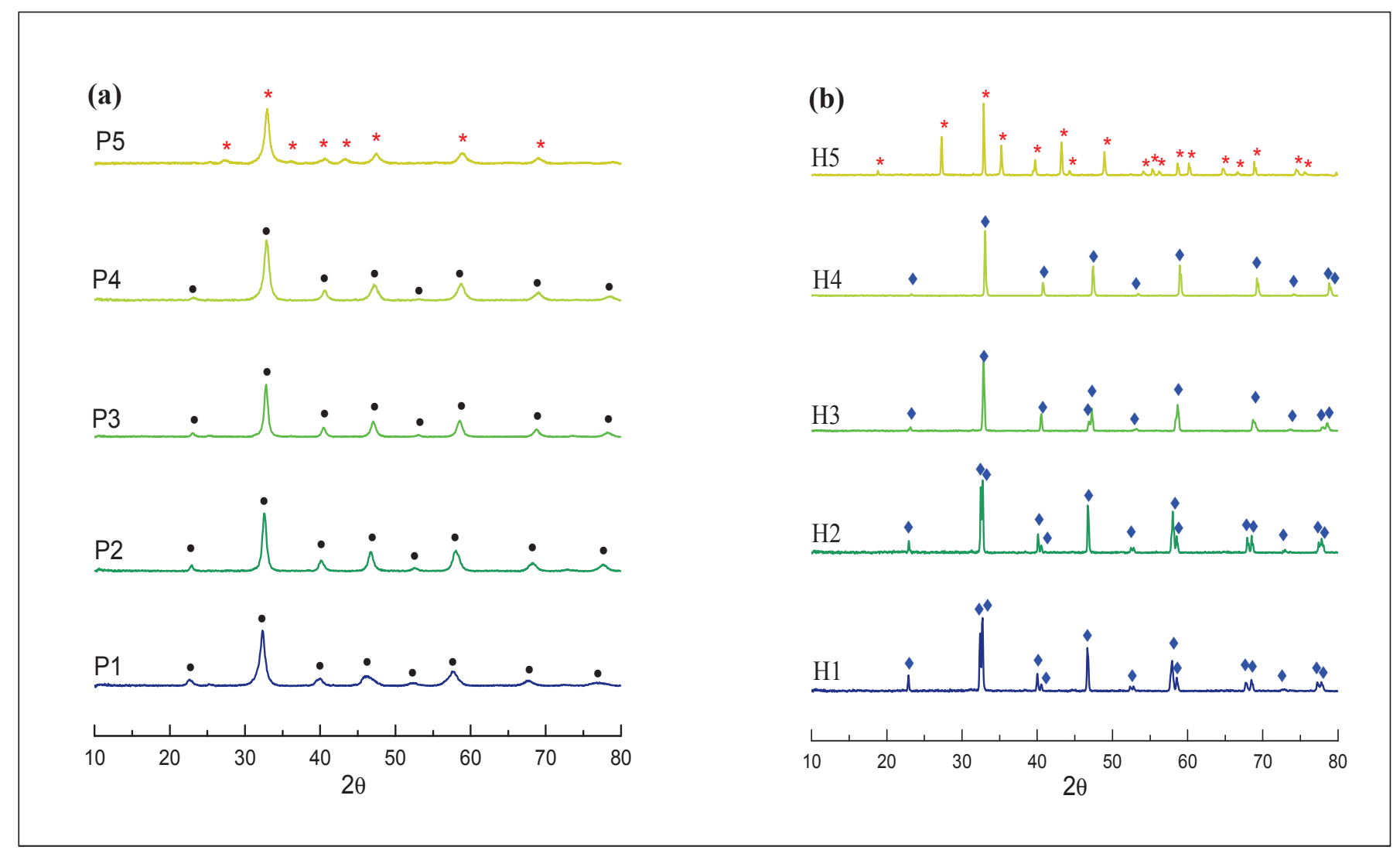

Figure 1 

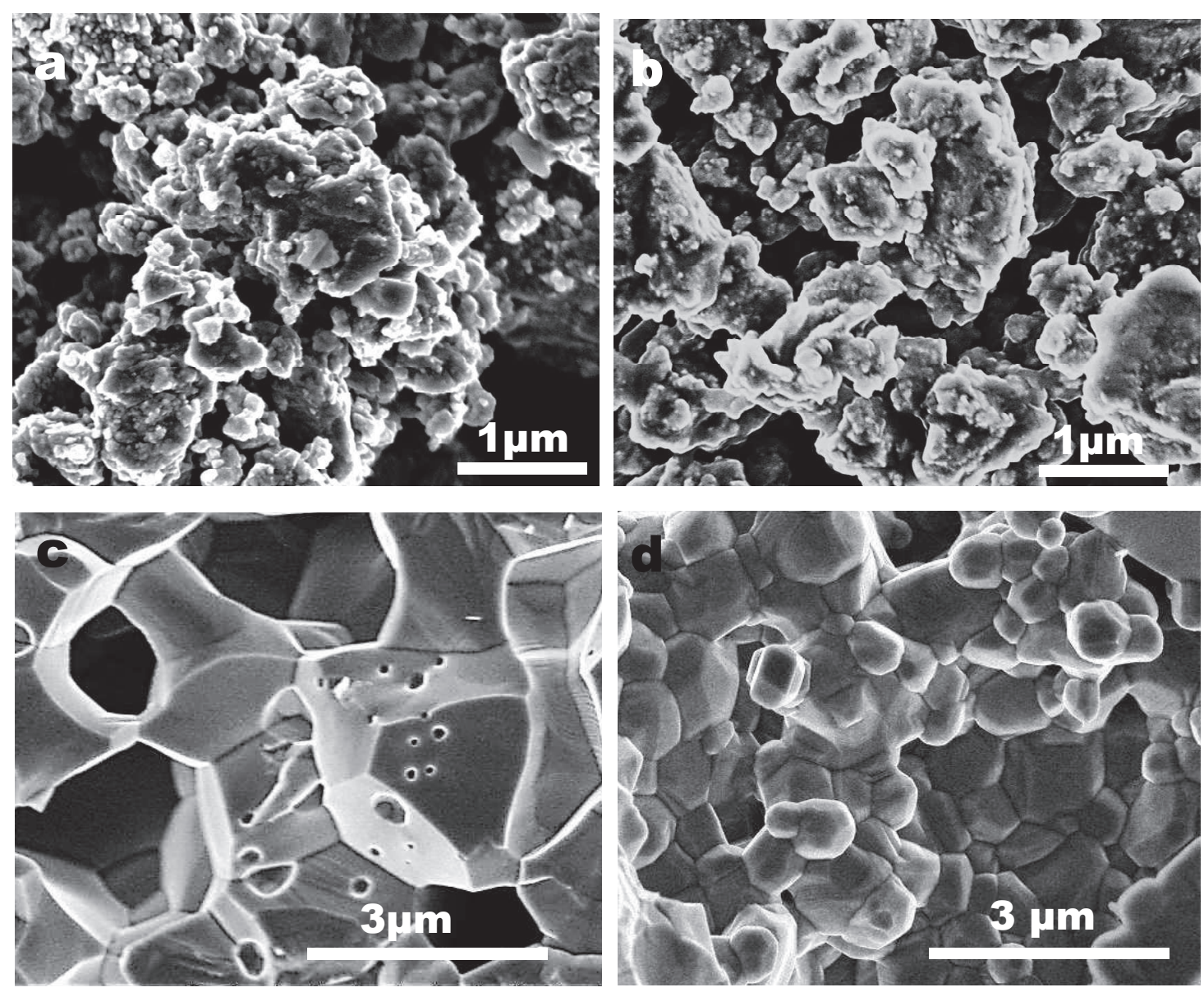

Figure 2 

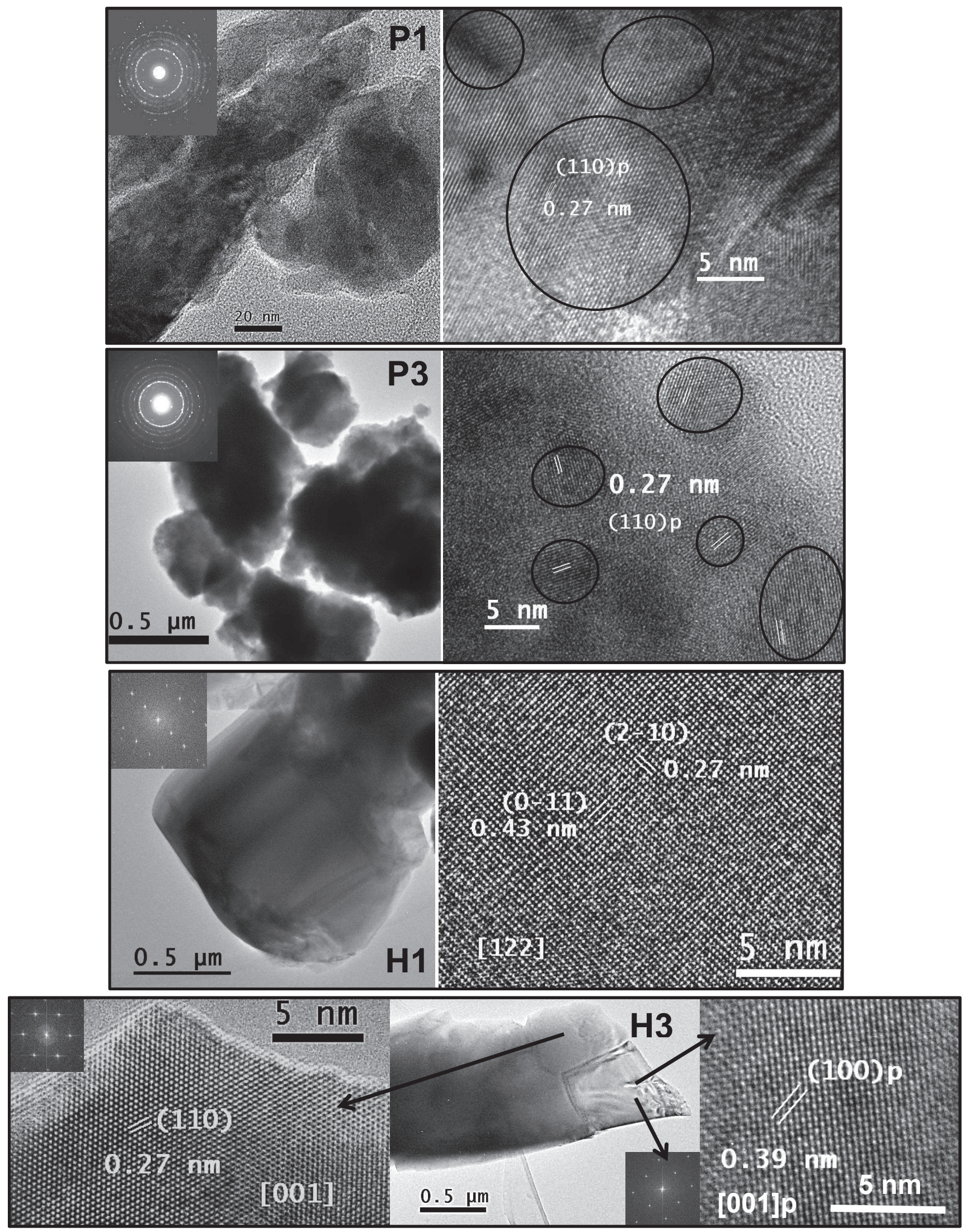

Figure 3 


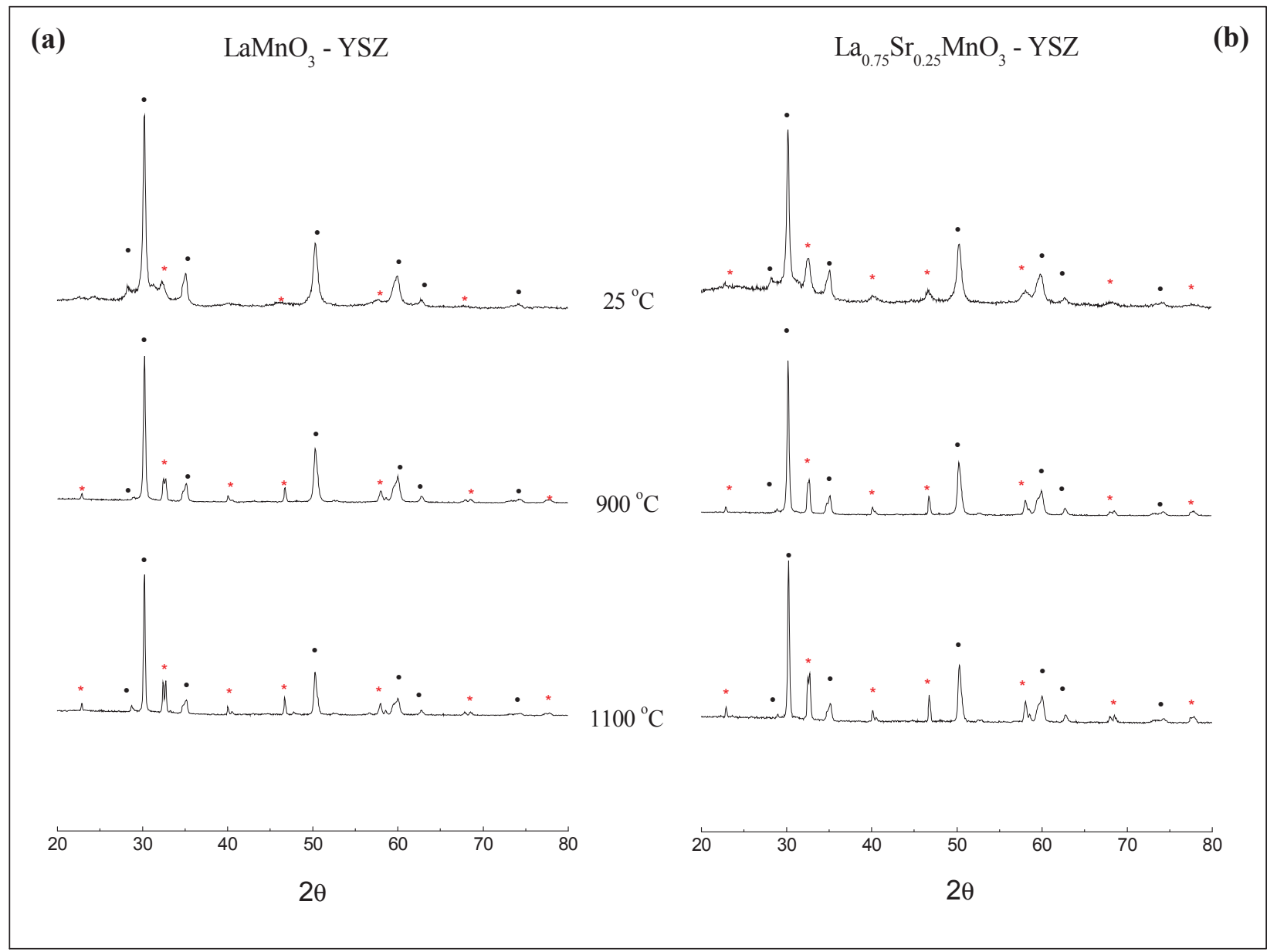

Figure 4 

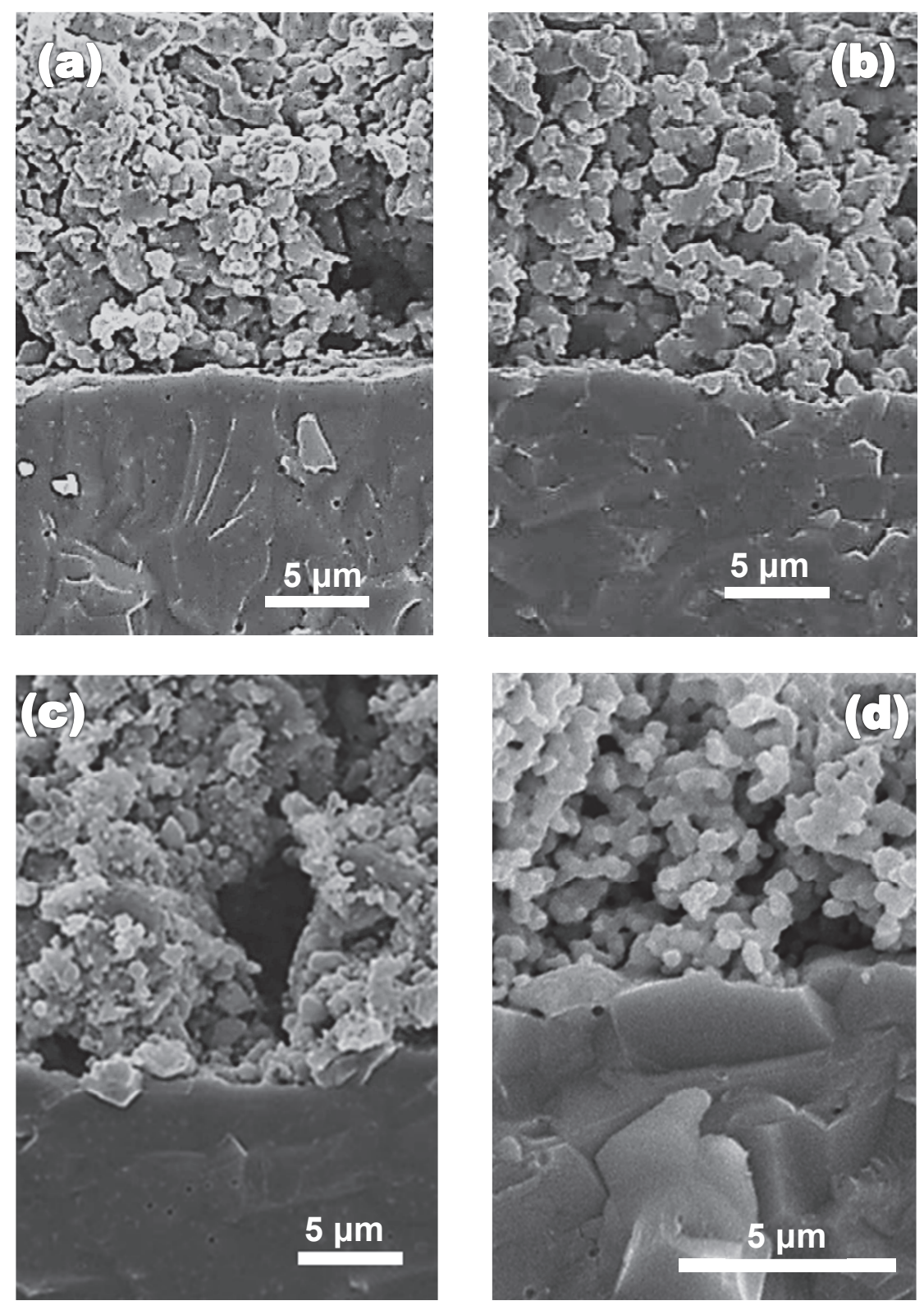

Figure 5 

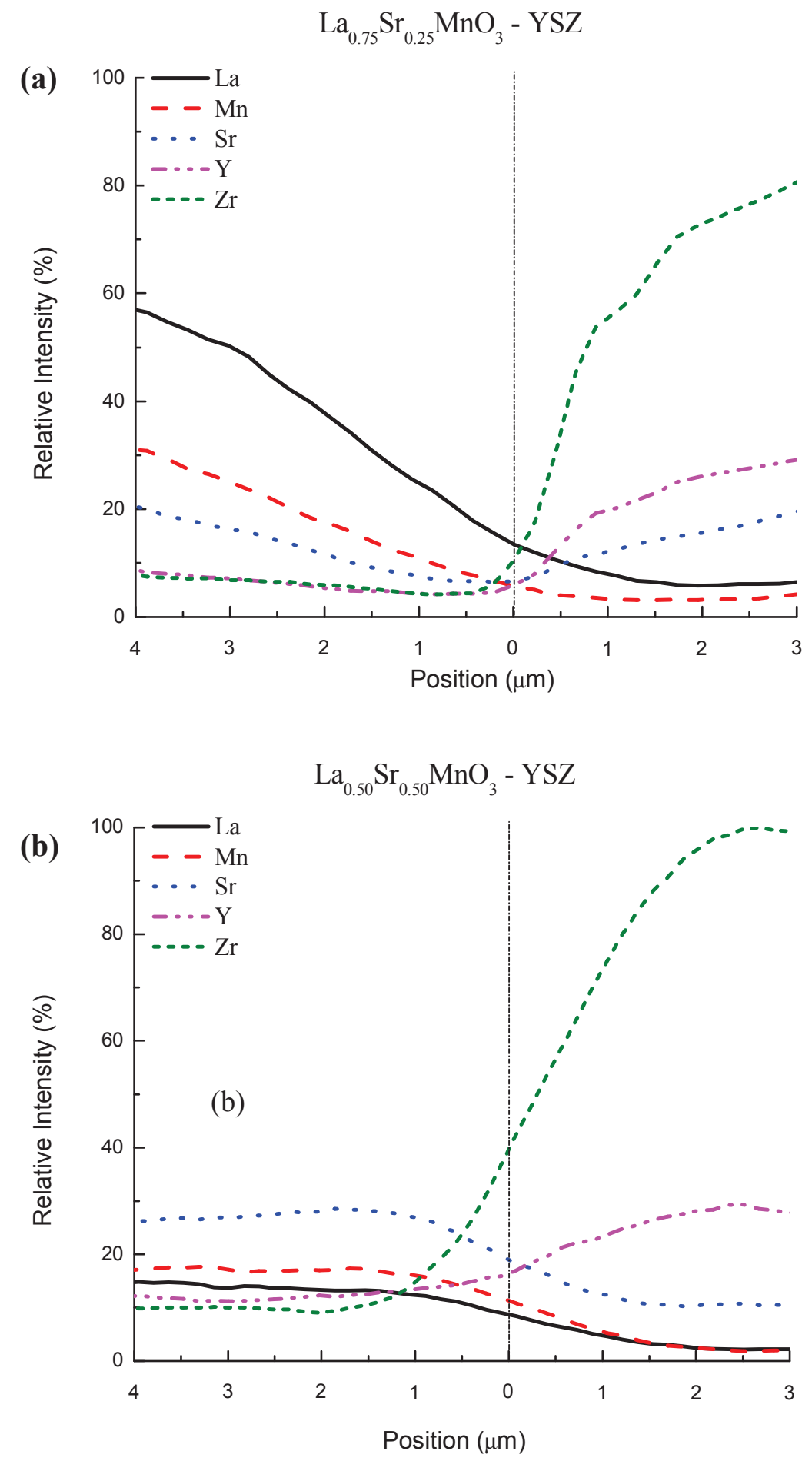

Figure 6 

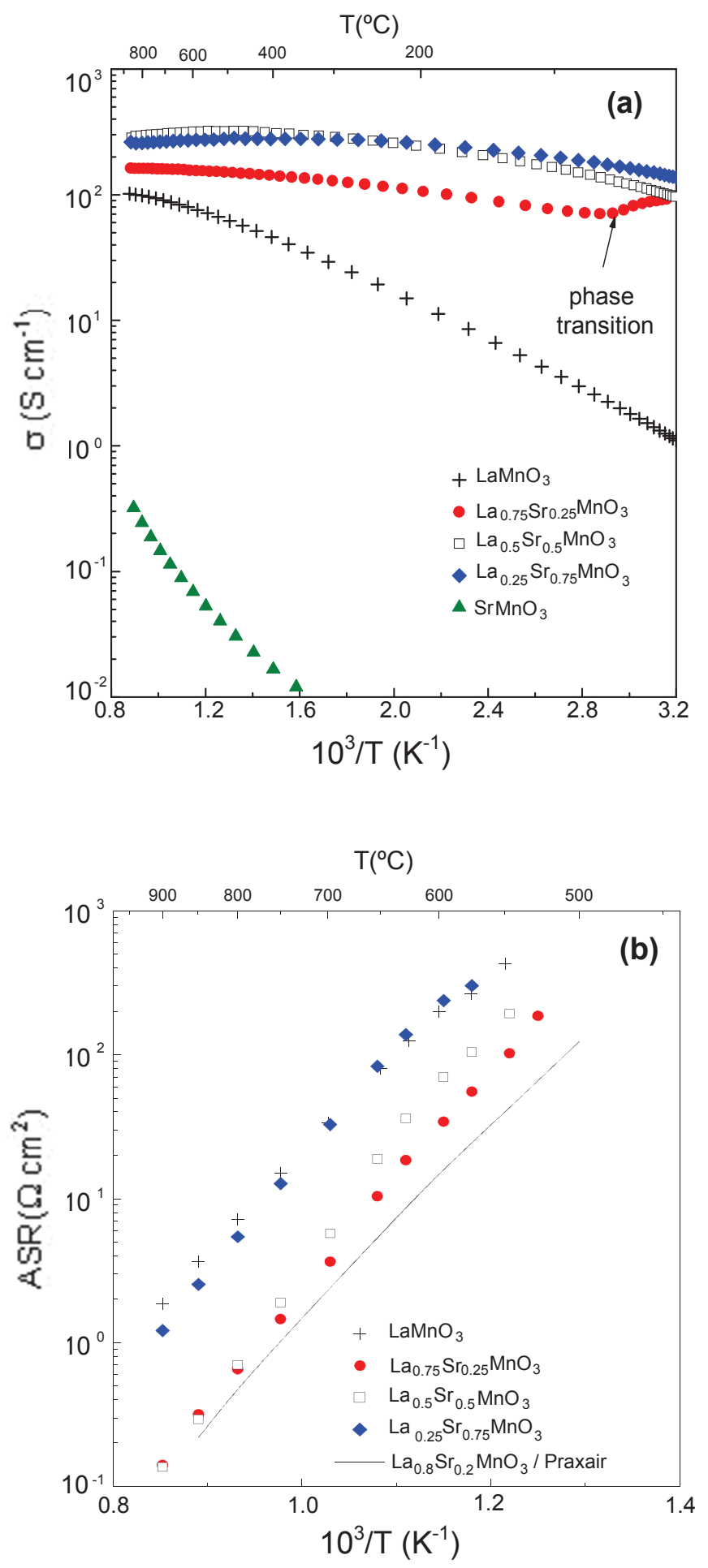

Figure 7 


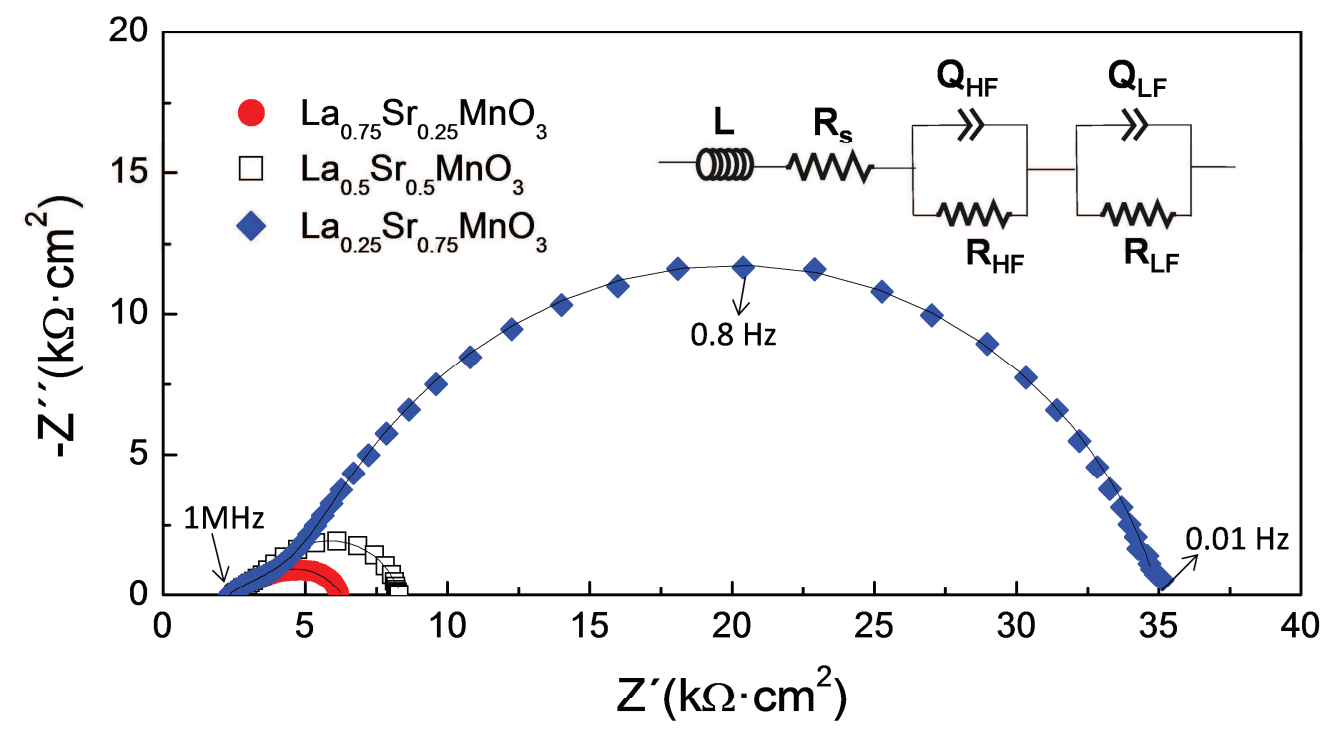

Figure 8 